\title{
Application of capacitive deionization technology to the removal of sodium chloride from aqueous solutions
}

\author{
C. H. Hou • C. Y. Huang • C. Y. Hu
}

Received: 22 August 2011/Revised: 15 November 2011/Accepted: 30 March 2012/Published online: 26 March 2013

(C) Islamic Azad University (IAU) 2013

\begin{abstract}
Capacitive deionization has been developed as a promising desalination alternative for removing ions from aqueous solutions. In this study, the evaluation of capacitive performance was carried out by galvanostatic charge/discharge and cyclic voltammetry experiments. The good capacitive and electrosorption behaviors suggest carbon aerogel not only treated as an electrical double layer capacitor, but also as a potential electrode in capacitive deionization processes. Also, the capacitive deionization characteristics indicate that electrosorption/regeneration can be controlled by polarization and depolarization of each electrode. It implies that sodium and chloride ions are electrostatically held to form electrical double layer on the surface of charged electrodes. The electrosorption performance at different applied voltages and solution concentrations was investigated. It is found that the removal of sodium chloride increases with increasing applied voltage and solution concentration, resulting from stronger electrostatic interactions, higher concentration gradient, and less double layer overlapping effect. Based on Langmuir isotherm, the equilibrium electrosorption capacity at $1.2 \mathrm{~V}$ is determined as $270.59 \mu \mathrm{mol} / \mathrm{g}$. Under this condition, due to the presence of micropores associated with the double layer overlapping, the effective surface area for electrosorption of ions at $1.2 \mathrm{~V}$ is estimated in the range of $12.18-14.25 \%$ of the BrunauerEmmett-Teller surface area. The results provide a fundamental understanding of electrosorption of ions and help promoting capacitive deionization technology for water purification and desalination.
\end{abstract}

C. H. Hou $(\bowtie) \cdot$ C. Y. Huang · C. Y. Hu

Department of Environmental Science and Engineering,

Tunghai University, Taichung 471, Taiwan

e-mail: chhou@thu.edu.tw
Keywords Capacitive deionization · Desalination . Electrosorption · Nanoporous carbon aerogel

\section{Introduction}

In recent years, one of the most critical problems affecting people throughout the world is the lack of clean, fresh water. In order to increase the fresh water supply, capacitive deionization (CDI) technology, or referred to electrosorption (defined as potential-induced sorption on the surface), has been identified as a promising desalination alternative to remove salt from aqueous solutions (Farmer et al. 1996a, b; Oren 2008). The CDI system is based on charge separation, associated with a rapid charge/discharge process to store and release large quantities of ions via porous electrodes (i.e., electrical double layer capacitors, EDLCs). More recently, a membrane capacitive deionization (MCDI) system, in which ion-exchange membranes are added onto a CDI system, has been developed to further increase desalination efficiency (Kim and Choi 2010; Li and Zou 2011). Generally, the CDI process operates at a low electrode potential and requires no high-pressure pump and chemicals. It presents several operational advantages, such as energy-saving, high capacity, easy regeneration of electrodes, and no secondary waste, over conventional desalination methods (e.g., reverse osmosis and electrodialysis) (Farmer et al. 1996a, b; Oren 2008; Anderson et al. 2010). The working concept of CDI, as shown in Fig. 1, is to force ions toward oppositely charged electrodes by applying an electric field, in which one electrode is positively charged to remove anions and the other electrode associated with negative charges takes responsibility to attract cations. After polarization of porous electrodes, ions are electrostatically separated from a solution and stored in 


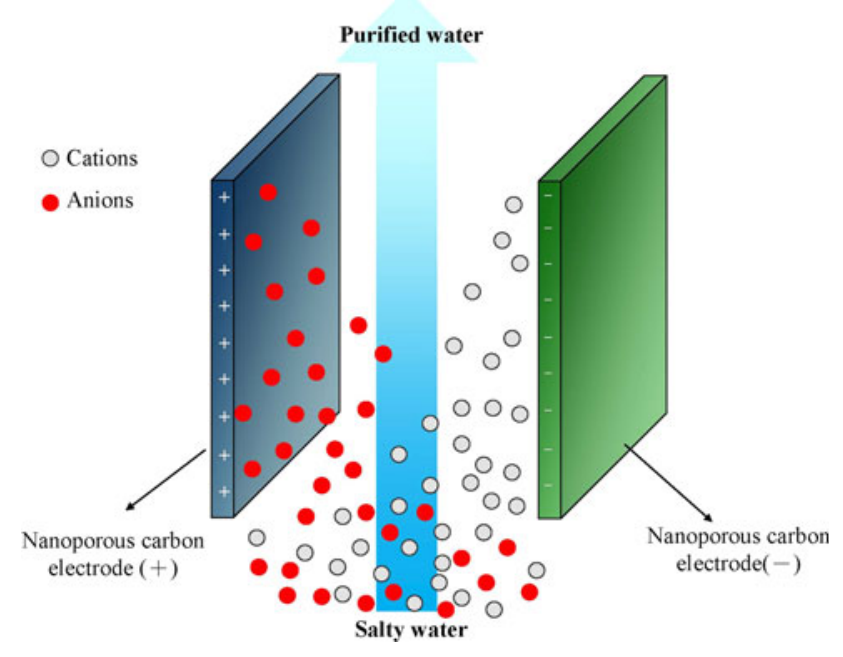

Fig. 1 Schematic diagram of the working principle of capacitive deionization with nanoporous carbon electrodes

the electrical double layer (EDL) at the electrode/solution interface. In principle, EDL is the cloud of ions with high local concentration of counter ions and low local concentration of coions, surrounding a charged surface. The thickness of the EDL is typically of a few nanometers (Hunter 2001). As a result, water (e.g., seawater or brackish water) leaving a CDI unit can be purified via the removal of charged dissolved substances. After porous electrodes are saturated with charged species, the electrodes can be regenerated by electrical discharge and then the ions can be quickly released into the bulk solution. Due to their microporosity and high specific surface area, nanoporous carbon materials (e.g., activated carbon, carbon fiber, carbon aerogel, and carbon nanotube) are ubiquitous and indispensable in separation technologies of environmental engineering. As molecular sieves for gas purification, carbon materials with selecting pore size distribution can separate target molecules by their difference in diffusion rate and adsorption capacity (Koresh and Soffer 1987). In addition, carbon materials, recognized as high-capacity adsorbents, are widely used in liquid separation to remove organic compounds and heavy metals from aqueous solutions (Okoye et al. 2010; Onundi et al. 2010).

Furthermore, the surface charge of carbon materials associated with good electrochemical characteristics can be easily regulated by applying electric potential or current to store ions. Therefore, taking advantages of the combination of high specific surface area, good electrical conductivity, and high electrochemical stability, makes carbon materials suitable as capacitor electrodes for the electrochemical storage (Frackowiak and Béguin 2001). Recently, another important application of carbon materials with nanostructure is to deionize salty water or remove charged contaminants by the CDI method (Farmer et al. 1997; Gabelich et al. 2002; Xu et al. 2008; Zou et al. 2008; Seo et al. 2010). Among carbon materials, carbon aerogels, synthesized via a sol-gel process using resorcinol-formaldehyde (RF) aerogels, constitute exceptional electrodes for electrosorption process in CDI (Jung et al. 2007; Xu et al. 2008). The features of carbon aerogels are low electrical resistivity $(<40 \mathrm{~m} \Omega \mathrm{cm})$, high specific surface area $(\sim 400-1,100$ $\mathrm{m}^{2} / \mathrm{g}$ ), and controlled pore size distribution $(<50 \mathrm{~nm})$, in correspondence with a three-dimensional network of interconnected carbon particles with small interstitial micropores (Frackowiak and Béguin 2001; Pröbstle et al. 2003). By using carbon aerogel electrodes, early studies by Farmer et al. (1996a, 1997) have succeeded to remove a variety of unwanted ions, including sodium chloride $(\mathrm{NaCl})$ and sodium nitrate $\left(\mathrm{NaNO}_{3}\right)$ from salty solutions and chromium ions from ground water. The best performance of carbon aerogel electrodes to remove ions was polarized at $+1.2 \mathrm{~V}$. They also reported that the regeneration of the CDI system can be achieved by reversing the electrode polarity: (a) cell discharge at $0 \mathrm{~V}$; (b) reverse polarization at $-1.2 \mathrm{~V}$; and (c) cell discharge at $0 \mathrm{~V}$. Gabelich et al. (2002) have shown a comprehensive work on the use of carbon aerogel for removing inorganic salts from laboratory and natural water. It was found that the ionic hydrated radius mainly determined the electrosorption capacity and selectivity in a competitive environment of multisolute systems; monovalent ions with smaller hydrated radii were more effectively removed from solution than multivalent ions with larger radii. In addition, the study showed only a few percent $\left(14-42 \mathrm{~m}^{2} / \mathrm{g}\right)$ of aerogel surface area $\left(400-590 \mathrm{~m}^{2} / \mathrm{g}\right)$ was available for ion sorption. In other words, surface area available for ion sorption can be determined by pore size distribution of carbon electrodes. High specific surface area is mainly contributed by the surface area of mesopores (pores of width between 2 and $50 \mathrm{~nm}$ ) and micropores (pores of width smaller than $2 \mathrm{~nm}$ ) present in carbon materials. When the pore size approaches the dimension of the EDL thickness, the effect of double layer overlapping has a significant influence on the electrosorption performance of carbon electrodes. Ying et al. (2002) introduced the cutoff pore width, defined as the largest pore size having zero capacity, to demonstrate the overlapping effect. The cutoff width decreased with increasing the solution concentration, and then smaller pores can contribute to electrosorption. A further understanding of the overlapping effect on capacitive behavior of carbon electrodes was carried out using voltammetric technology (Yang et al. 2003; Hou et al. 2006). EDL overlapping reduces the double layer capacitance in terms of the number of ions electroadsorbed within carbon electrodes. The relation between pore size distribution and carbon capacitance is of great significance. Related to water desalination, micropores exhibited a lower charging 
rate of electrosorption processes as compared with mesopores (Noked et al. 2009). The concept of electrosorption is an attractive combination of the high sorption capacity and the electrical conductivity of carbons. However, the fundamental mechanism behind the electrosorption process of ions onto nanoporous carbon electrodes is still not wellunderstood. In this study, carbon aerogel as one of the most common electrodes in the CDI process was used for water desalination. The object of this study is to present the fundamental aspect of electrosorption process using nanoporous carbon aerogel. Unlike EDLC system, the electrochemical characterization of carbon electrodes in the CDI system is relatively complicated to analyze due to their low solution concentration and conductivity. In that regard, voltammetric experiments, including galvanostatic charge/ discharge measurement and cyclic voltammetry, were carried out to analyze the capacitive behavior of carbon electrode during the electrosorption process. Furthermore, electrosorption experiment was performed with a CDI unit cell to assess the impact of such parameters as operating voltage and solution concentration on the electrosorption behavior of sodium and chloride ions in the CDI process. This research was carried out at the Department of Environmental Science and Engineering, Tunghai University, from August 2010 to July 2011.

\section{Materials and methods}

\section{Carbon aerogel and characterization}

The carbon electrode used in this study was a commercial carbon aerogel obtained from Marketch (Port Townsend, WA). For characterization, scanning electron microscope (SEM) image was collected on a JEOL, Inc., JSM-7401F electron microscope. A surface and pore size analyzer (TriStar II 3020, Micromeritics Inc., USA) was employed to obtain the nitrogen adsorption-desorption isotherm, pore size distribution, and specific surface area via the Brunauer-Emmett-Teller (BET) method from the nitrogen adsorption data in the relative pressure range of $p / p_{0}=0.99$. The pore size distribution curve was derived from the adsorption branch of the isotherm based on the BarrettJoyner-Halenda (BJH) method.

\section{Voltammetric experiments}

Electrochemical characteristics of carbon aerogel in the electrosorption process were investigated by galvanostatic charge/discharge and cyclic voltammetry experiments. The voltammetric measurements were carried out using a potentiostat (CHI 627D, CH Instruments, Inc., USA) and a electrochemical cell that was consisted with a three-electrode arrangement: the working electrode was a platinum wire attached to a small piece of carbon material in aqueous solution, the counter electrode was a large carbon material with another platinum wire, and the reference electrode was the BAS model RE-1 $(\mathrm{Ag} / \mathrm{AgCl}$ electrode in a $3 \mathrm{M} \mathrm{NaCl}$ electrolyte solution). To test the charge/discharge performance, the electrochemical cell was charged with constant current $(0.5 \mathrm{~A} / \mathrm{g})$ up to voltage of $0.8 \mathrm{~V}$, and discharged with constant current $(-0.5 \mathrm{~A} / \mathrm{g})$ down to a voltage of $0.0 \mathrm{~V}$. Cyclic voltammograms for assessing the EDL capacitance of carbon electrode was performed between +0.6 to $-0.4 \mathrm{~V}$ with various scan rates ranged from 5 to $20 \mathrm{mV} / \mathrm{s}$. In another experiment, cyclic voltammograms were obtained using a two-electrode configuration (without a reference electrode) on the same carbon aerogel electrodes to study the capacitive behavior in electrosorption. The aqueous solutions were $\mathrm{NaCl}$ (Merck) solutions at different concentrations. All experiments were conducted at room temperature.

\section{Electrosorption experiments of capacitive deionization}

Electrosorption experiments for $\mathrm{NaCl}$ solutions were performed in a continuously recycling system. The system was composed of an electrosorption unit cell, a peristaltic pump (MP-1000, EYELA, Japan), a conductivity meter (SC-2300, Suntex, Taiwan), and a potentiostat (CHI 627D). The electrosorption unit cell consisted of a pair of carbon aerogel sheets and the two oppositely planar electrodes were separated by a $1.0 \mathrm{~mm}$ spacer for solution flow. The effective dimension of the planar carbon aerogel electrodes was $7 \times 7 \mathrm{~cm}^{2}$. In addition, the assembly of one half of the electrosorption unit cell followed this sequence: Plexiglas cover, titanium plate, carbon electrode, Viton gasket with hole, and central hollow Plexiglas. In each experiment, the total solution volume was $30 \mathrm{~mL}$ and the solution was continuously pumped by a peristaltic pump with a flow rate of $10 \mathrm{~mL} / \mathrm{min}$. The variation of solution conductivity was monitored at the outlet of the cell by using an online conductivity meter. Thus, the concentration of $\mathrm{NaCl}$ solution can be obtained according to the linear relationship between electrolyte concentration and conductivity, via a calibration table made prior to experiment. Each experiment was performed until the conductivity variation was not apparent to reach an equilibrium state. Several electrosorption experiments under identical conditions were repeated to confirm the reproducibility of the results. In our experiment, the electrosorption capacity, defined as the amount of ions electroadsorbed per gram of the carbon electrode, was defined as follows:

Electrosorption capacity $(\mu \mathrm{mol} / \mathrm{g})=\frac{\left(C_{0}-C_{\mathrm{e}}\right) \cdot V}{m}$ 
where $C_{0}$ and $C_{\mathrm{e}}$ are the initial and equilibrium concentration, respectively. $V$ is the volume of solution and $\mathrm{m}$ is the mass of carbon aerogel electrode.

\section{Results and discussion}

\section{Porous structure}

The surface area and pore size distribution were determined by the nitrogen adsorption-desorption isotherm of the carbon aerogel electrode, as shown in Fig. 2.

As observed, the BET surface area reaches $460.34 \mathrm{~m}^{2} / \mathrm{g}$ and the pore size distribution broadly ranges from micropores to mesopores. The percentage of the surface area attributed to mesopores to the total surface area is $52.18 \%$. Also, the inset image of SEM micrograph shows the highly cross-linked networks and the cracks in the surface morphology are derived from pyrolysis of the shrinking RF-aerogels (Pröbstle et al. 2003). The roles of micropores and mesopores are different during electrosorption process. The presence of micropores is an essential feature in the high specific surface area of carbon electrode. On the other hand, mesopores have fast charging rate of ions in the electrosorption process (Hou et al. 2006). A carbon electrode, composed of both micropores and mesopores, constitutes a favorable capacitor electrode material due to both high double layer capacity and high electrosorption rate (Noked et al. 2009; Villar et al. 2011). Because of the comparable amount of micropores and mesopores, the nanoporous structure makes the carbon aerogel electrode a desirable candidate for electrosorption of ions.

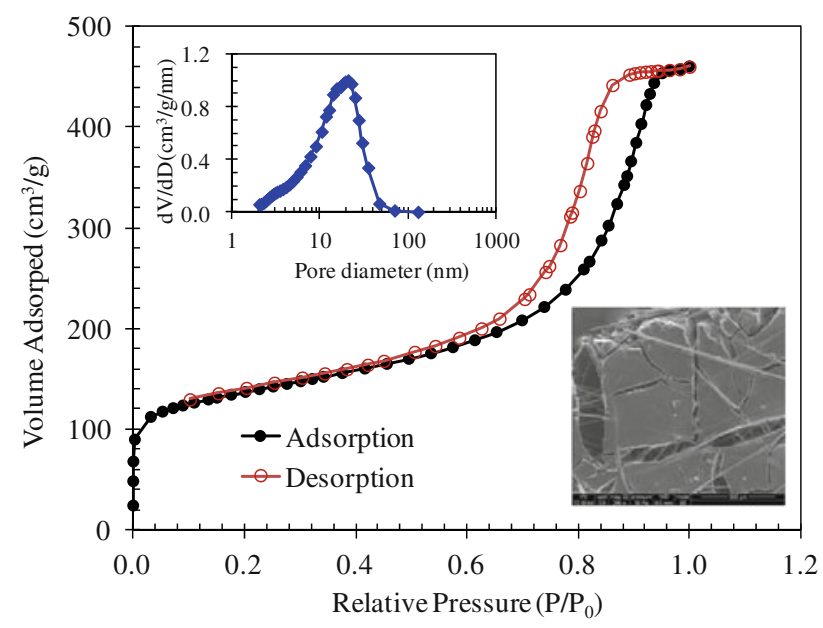

Fig. 2 Nitrogen adsorption-desorption isotherm, BJH pore size distribution, and SEM image for carbon aerogel electrode
Electrochemical performance

A nanoporous carbon electrode can be regarded as an EDLC for energy storage, in which the double layer formation at charged electrode surface determines the capacitive behavior and the specific capacitance. Figure $3 a$ presents the galvanostatic charge/discharge cycle of carbon aerogel at a current density of $0.5 \mathrm{~A} / \mathrm{g}$ with voltages in the range of 0.0 and $0.8 \mathrm{~V}$. At a concentrated $\mathrm{NaCl}$ solution of $1 \mathrm{M}$, the charge/discharge profile is very symmetric and well-trained triangular shape. The linear voltage-time dependence demonstrates a typical correct type for capacitor charge/discharge shape without ohmic drop during reversing of polarization (Frackowiak and Béguin 2001). Figure $3 \mathrm{~b}$ shows the cyclic voltammograms of carbon aerogel in $1 \mathrm{M} \mathrm{NaCl}$ solution at different scan rates. At $5 \mathrm{mV} / \mathrm{s}$ scan rate, an expected rectangular shape of $\mathrm{CV}$ curves without any peaks can be observed, ensuring the
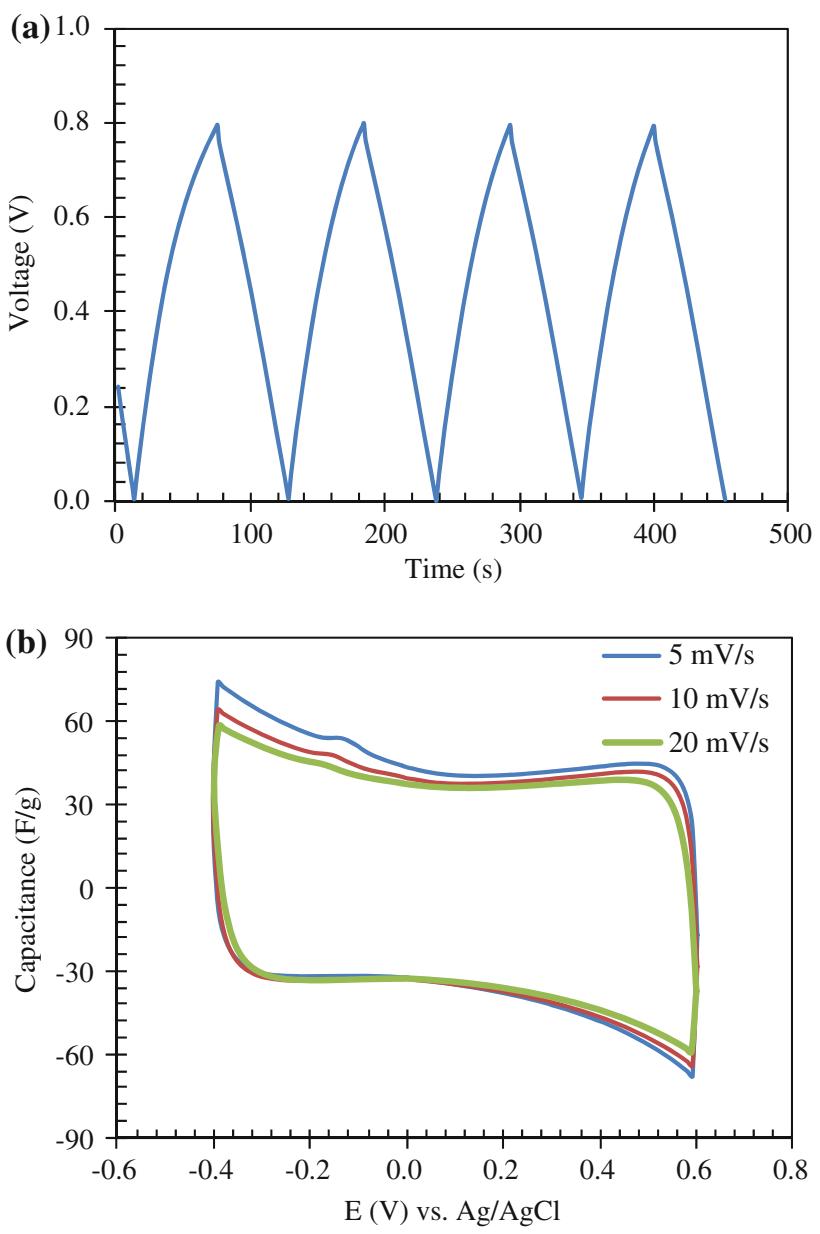

Fig. 3 Electrochemical performance of carbon aerogel measured by voltammetric experiments in $1 \mathrm{M} \mathrm{NaCl}$ electrolyte solution using a three-electrode configuration: a charge/discharge curve with a current load of $0.5 \mathrm{~A} / \mathrm{g}$, and $\mathbf{b}$ cyclic voltammograms with various scan rates of 5,10 and $20 \mathrm{mV} / \mathrm{s}$ 
specific capacitance as a result of the ion accumulation in the EDL region without Faradic reaction. The feature also implies that electrosorption of both $\mathrm{Na}^{+}$cations and $\mathrm{Cl}^{-}$ anions follow the same mechanism of double layer formation in this potential range. Moreover, an increase of scan rates from 5 to $20 \mathrm{mV} / \mathrm{s}$ does not distort the rectangular shape, representing an ideal double layer capacitive behavior. On the other hand, the calculated specific EDL capacitances for $5,10,20 \mathrm{mV} / \mathrm{s}$ are $74.23,64.25$, and 58.33 $\mathrm{F} / \mathrm{g}$ at $-0.4 \mathrm{~V}$, respectively. The explanation is that, at low scan rate, micropores have more contribution to provide the electrode/electrolyte interface for EDL formation (Yang et al. 2003).

To study the voltammetry characteristics under the similar electrochemical condition with CDI process, cyclic voltammetry experiments were performed in a two-electrode arrangement at $10 \mathrm{mV} / \mathrm{s}$ scan rate. In each experiment, the two same carbon aerogel electrodes were used as working and counter electrodes, respectively. The effect of applied potential on capacitive characteristics is shown in Fig. $4 \mathrm{a}$, where a $0.02 \mathrm{M} \mathrm{NaCl}$ solution was used. As can be seen, the typical double layer capacitive behavior with a rectangular shape can be found in all the $\mathrm{CV}$ curves in the applied potential range between 0.0 and $1.2 \mathrm{~V}$. It should be emphasized that the variation of applied potential range affects the electrosorption and desorption behavior of $\mathrm{NaCl}$. The specific double layer capacitance increases with increasing the polarization of carbon aerogel electrodes. For example, when the applied potential range increases from 0.2 to $1.2 \mathrm{~V}$, the specific capacitance at $0.0 \mathrm{~V}$ is gradually enhanced from 3.63 to $6.43 \mathrm{~F} / \mathrm{g}$, respectively. Figure $4 \mathrm{~b}$ shows the changes in capacitive performance at various electrolyte concentrations of $\mathrm{NaCl}$ solution. One can see that the cyclic voltammogram maintains a rectangular shape in $0.03 \mathrm{M} \mathrm{NaCl}$ solution. However, when a $0.002 \mathrm{M}$ concentration is used, the shape of rectangle is distorted due to the uncompensated resistance of the low concentration solution. Moreover, as the concentration of $\mathrm{NaCl}$ increases, the specific capacitance increases correspondingly. For example, when the concentrations are $0.002,0.01$, and $0.02 \mathrm{M}$, the specific capacitances achieve 3.31, 5.49, $6.43 \mathrm{~F} / \mathrm{g}$, respectively. Furthermore, a comparison of cyclic voltammograms in 0.02 and $0.03 \mathrm{M} \mathrm{NaCl}$ solutions indicates that no significant change in capacitive performance can be found. The specific capacitance of $0.03 \mathrm{M} \mathrm{NaCl}$ solution only slightly shifts to $6.58 \mathrm{~F} / \mathrm{g}$. Thus, if a high electrolyte concentration is conducted, the electrode surface could be saturated in electrosorption process.

Overall, the good electrode performance characteristics present in this study ensure the carbon aerogel as a suitable carbon electrode for electrical capacitor and electrosorption of $\mathrm{NaCl}$. The specific double layer capacitance strongly depends on applied potential and solution concentration,
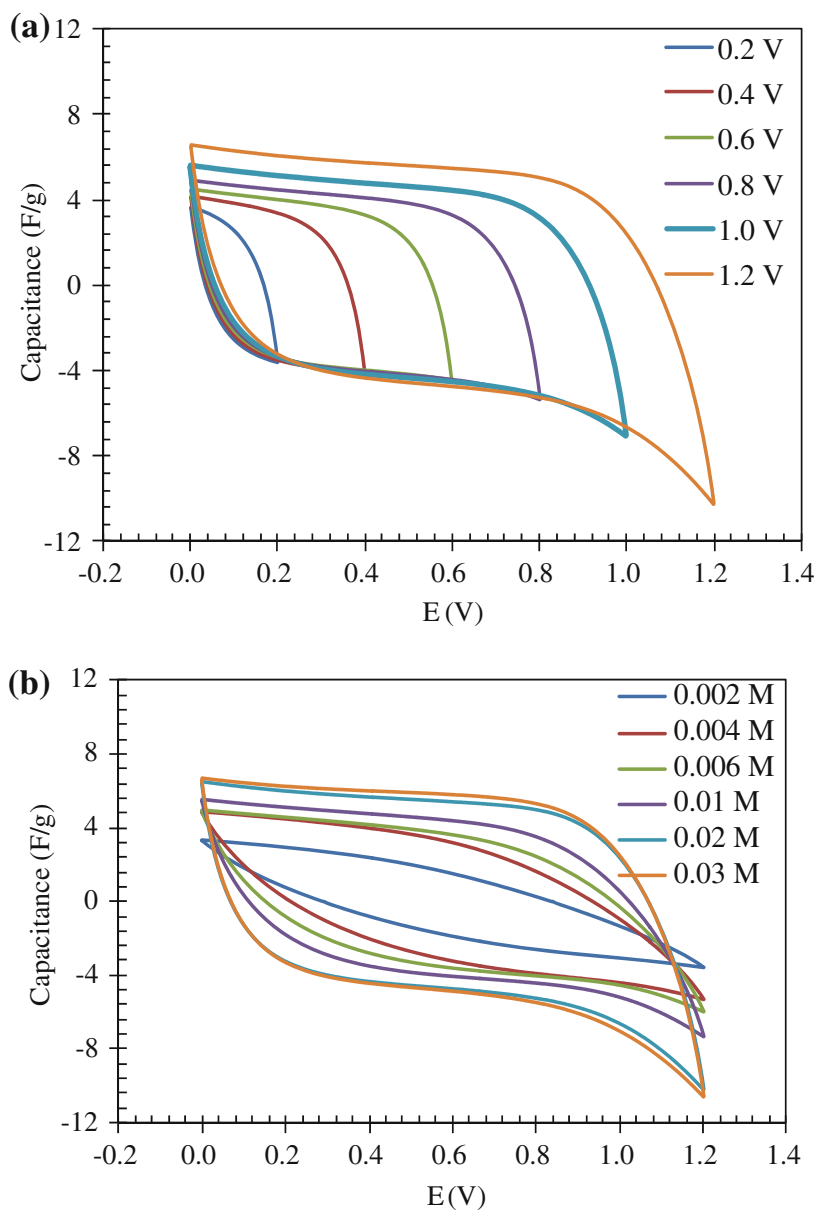

Fig. 4 Cyclic voltammograms obtained by using a two-electrode configuration at a scan rate of $10 \mathrm{mV} / \mathrm{s}$ for a $0.02 \mathrm{M} \mathrm{NaCl}$ solution within different applied potential ranges, and $\mathbf{b}$ various $\mathrm{NaCl}$ solution concentrations in the potential range of $0.0-1.2 \mathrm{~V}$

with respect to ions accumulated within carbon electrode. Also, no electrically driven redox reaction takes place in charge/discharge process, meaning that the mechanism behind ion separation from aqueous solutions is a result of purely electrostatic interactions of ions and charged pore surface rather than electrochemical reaction.

\section{Capacitive deionization characteristics of $\mathrm{NaCl}$}

When the pair of electrodes had a potential difference in the range of $1.2-1.4 \mathrm{~V}$, the carbon aerogel-based CDI process was very effective for removing the salt from aqueous solutions (Farmer et al. 1996a; Ying et al. 2002; $\mathrm{Xu}$ et al. 2008; Gabelich et al. 2002). The greater cell voltage usually leads to higher removal efficiency. However, water electrolysis could take place with high applied voltage. Farmer et al. (1996a) also indicated that the optimum working voltage for carbon aerogel-based CDI was $1.2 \mathrm{~V}$. With respect to this point, the amplitude of the applied voltage was $1.2 \mathrm{~V}$ in this experiment. No water 
electrolysis or electrochemical reactions occurred on the electrode surface. Additionally, in other experiments, the applied voltage was increased in steps of $0.2 \mathrm{~V}$ from 0.0 to $1.2 \mathrm{~V}$ to investigate the effect of applied voltage on CDI performance. Figure 5 shows the typical electrosorption characteristics of $\mathrm{NaCl}$ removal and regeneration cycles of carbon aerogel electrodes at $1.2 \mathrm{~V}$ in the CDI process. The experiment was conducted with an $\mathrm{NaCl}$ solution that had a conductivity of $200 \mu \mathrm{s} / \mathrm{cm}$. As can be seen, the solution conductivity significantly dropped to about $74 \mu \mathrm{s} / \mathrm{cm}$ during the charge process at $60 \mathrm{~min}$. It indicates that by applying a potential difference across the two carbon aerogel electrodes, the positively charged electrode adsorbs $\mathrm{Cl}^{-}$ions, while the negative electrode attracts $\mathrm{Na}^{+}$ions. Also, when an electrical field is applied, the current arises sharply due to the transport of $\mathrm{NaCl}$ ions from the solution to the charged surface of electrode (Villar et al. 2011). After a short period of time, the rapid decay of current can be observed until the two oppositely charged electrodes are in equilibrium with the solution. It means that a new equilibrium state is reached by completely forming the double layer on the surface of the electrode/electrolyte interface. Under this condition, the $\mathrm{Na}^{+}$and $\mathrm{Cl}^{-}$ions are mainly electroadsorbed in the diffuse layer of the EDL. In addition, as shown in Fig. 5, when the electrosorption experiment was carried out at an applied voltage of $1.2 \mathrm{~V}$ for $60 \mathrm{~min}$, the total charges supplies to the CDI cell was measured as 227.6 coulombs in one charge process. In this case, the specific energy consumption in CDI is calculated as $2.53 \mathrm{kWh} / \mathrm{m}^{3}$.

Upon the electrode depolarization at $0.0 \mathrm{~V}$, the solution conductivity rapidly returns to its initial value, and at the same time, the current dramatically becomes zero. It indicates that the desorption behavior is also a rapid process, in which ions are quickly released from the double layer region back to the solution. Because the reversibility plays a key role in the practical use of CDI process, it is very important that the regeneration can be achieved by discharging carbon aerogel electrodes. Figure 5 illustrates the electrosorption/regeneration test by repeating several charge/discharge procedures. The same pattern in all cycles can be observed, confirming that the electrosorption is a reversible process. The electrosorption characteristics are consistent with the results obtained by voltammetry experiments: the mechanism behind $\mathrm{NaCl}$ ions stored within the carbon electrodes mainly lies on the EDL formation caused by electrostatic interactions.

Effects of applied potential and solution concentration on electrosorption

Applied potential and solution concentration are the key factors affecting the electrosorption behavior in CDI
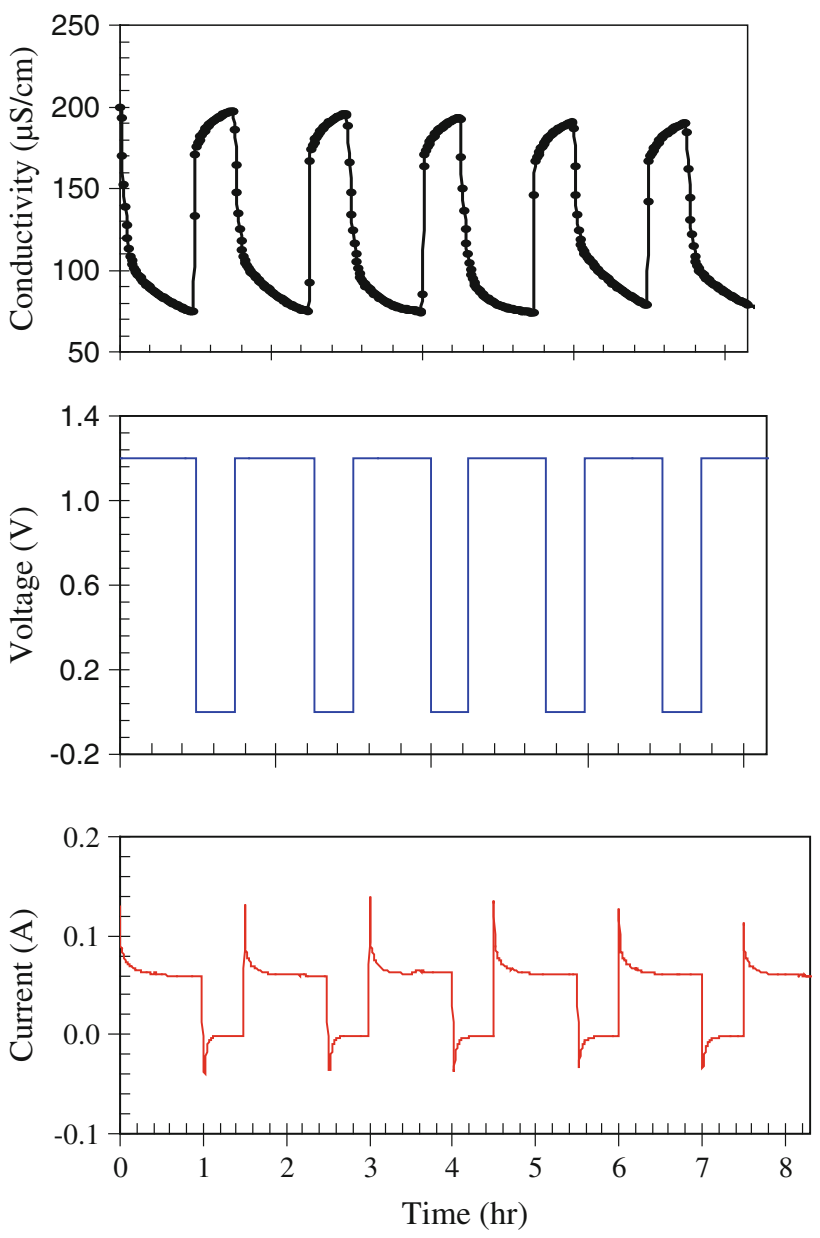

Fig. 5 Multiple electrosorption/regeneration cycles of $\mathrm{NaCl}$ solution at the applied voltage of $1.2 \mathrm{~V}$

process. To investigate the effect of applied potential on the removal of $\mathrm{NaCl}$, electrosorption experiments were conducted at various voltages of $0.0,0.2,0.4,0.6,0.8,1.0$, and $1.2 \mathrm{~V}$, as depicted in Fig. 6a, b. Each experiment was conducted in $0.002 \mathrm{M} \mathrm{NaCl}$ solution and run for $60 \mathrm{~min}$ to reach a new equilibrium state. As expected, the solution conductivity is decreased with the operating time. Increasing the applied potential increases the amount of dropped conductivity, as shown in Fig. 6a. By converting the difference between the initial conductivity and final conductivity, the electrosorption capacity at equilibrium can be calculated according to Eq. 1. When the voltage increases from $0.0,0.4,0.8$, to $1.2 \mathrm{~V}$, the electrosorption capacities reach $7.62,17.26,53.82$ and $80.74 \mu \mathrm{mol} / \mathrm{g}$, respectively. One can conclude that increasing the applied voltage enhances the electrosorption capacity due to stronger electrostatic interaction.

Fig. 7 shows the electrosorption isotherms at 0.8 and $1.2 \mathrm{~V}$, and the initial concentration was changed in the range of $0.002-0.03 \mathrm{M}$. As the initial solution concentration increases from 0.002 to $0.02 \mathrm{M}$, the electrosorption 
capacity at $1.2 \mathrm{~V}$ is enhanced from 80.74 to $231.54 \mu \mathrm{mol} / \mathrm{g}$, respectively.

Thus, the amount of $\mathrm{NaCl}$ electrosorbed onto carbon aerogel electrodes increases with increasing solution concentration. However, it is noted that, if the solution concentration is very high, the surface of carbon electrode for $\mathrm{NaCl}$ electrosorption will be eventually saturated (Zou et al. 2008; Li et al. 2010). In that regard, electrosorption behavior was further validated using Langmuir and Freundlich isotherms. Langmuir isotherm, suggesting the monolayer sorption occurred on a homogeneous surface with identical sorption sites and sorption energy, is given using the following formula:

$q=\frac{q_{\mathrm{m}} K_{\mathrm{L}} C_{\mathrm{e}}}{1+K_{\mathrm{L}} C_{\mathrm{e}}}$

where $q$ and is the amount of $\mathrm{NaCl}$ adsorbed at equilibrium in electrosorption process. $q_{\mathrm{m}}$ is the maximum sorption capacity to complete monolayer coverage. $K_{\mathrm{L}}$ is the Langmuir constant related to the sorption energy. Freundlich isotherm considered as a semi-empirical equation is represented by:
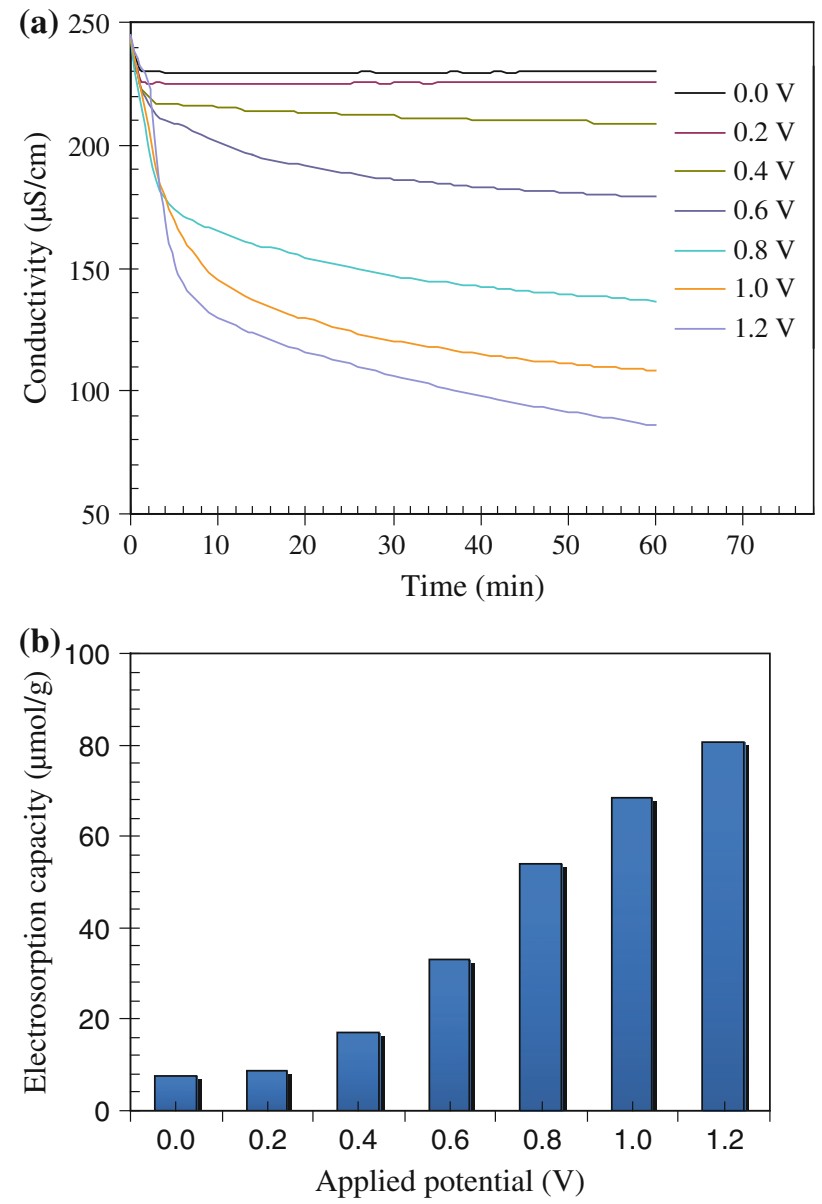

Fig. 6 Electrosorption of $\mathrm{NaCl}$ onto carbon aerogel electrode for a the conductivity variation and $\mathbf{b}$ the electrosorption capacity at different applied potentials

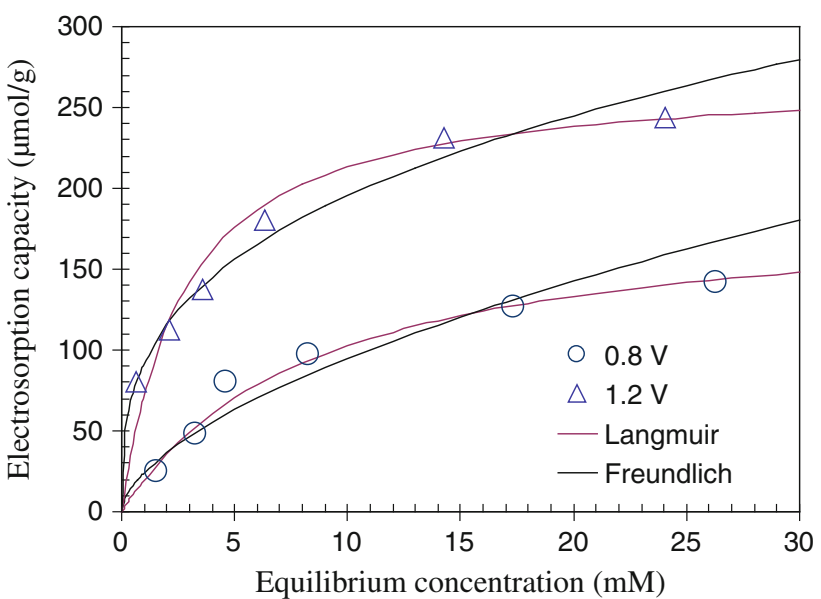

Fig. 7 The electrosorption isotherms of $\mathrm{NaCl}$ onto carbon aerogel electrode at 0.8 and $1.2 \mathrm{~V}$

$q=K_{\mathrm{F}} C_{\mathrm{e}}^{1 / n}$

where $K_{\mathrm{F}}$ and $n$ are the Freundlich constants related to sorption capacity and intensity, respectively. Table 1 lists the calculated parameters and regression coefficients $\left(r^{2}\right)$ of Langmuir and Freundlich isotherms in electrosorption. It suggests that both Langmuir and Freundlich models agree well with the experimental data. Based on the Langmuir model, the maximum capacity $\left(q_{\mathrm{m}}\right)$ of $\mathrm{NaCl}$ electrosorption at $1.2 \mathrm{~V}$ is $270.59 \mu \mathrm{mol} / \mathrm{g}$, which is much higher than that of $190.01 \mu \mathrm{mol} / \mathrm{g}$ at $0.8 \mathrm{~V}$.

It should be noted that the BET surface area, determined by nitrogen adsorption isotherm, is not the true surface area available for ion electrosorption. The saturation of surface area occupied by ions can be calculated by multiplying the electrosorption capacity by Avogadro's number and the two-dimension area based on the hydrated radius of ions (Gabelich et al. 2002; Xu et al. 2008). In this study, the saturation capacity of $\mathrm{NaCl}$ is referred to the maximum sorption capacity of Langmuir isotherm. The hydrated radius of $\mathrm{Na}^{+}$and $\mathrm{Cl}^{-}$ions are 3.58 and $3.31 \AA$, respectively. As a result, the surface area coverage for $\mathrm{Na}^{+}$and $\mathrm{Cl}^{-}$ions at $1.2 \mathrm{~V}$ is about 65.58 and $56.06 \mathrm{~m}^{2} / \mathrm{g}$, which represents only 14.25 and $12.18 \%$ of the measured BET surface area. Much of the surface area is attributed to the presence of micropores that are not penetrated by ions due to ion-exclusion and EDL overlapping effects (Ying et al.

Table 1 The isotherm parameters of $\mathrm{NaCl}$ electrosorption at different potentials

\begin{tabular}{lllllllll}
\hline E $(\mathrm{V})$ & \multicolumn{2}{l}{ Langmuir } & & & \multicolumn{3}{l}{ Freundlich } \\
\cline { 2 - 3 } & $q_{\mathrm{m}}(\mu \mathrm{mol} / \mathrm{g})$ & $K_{\mathrm{L}}(\mathrm{L} / \mathrm{mol})$ & $r^{2}$ & & $K_{\mathrm{F}}$ & $n\left(10^{3}\right)$ & $r^{2}$ \\
\hline 0.8 & 190.01 & 117.29 & 0.976 & & 1.70 & 1.42 & 0.874 \\
1.2 & 270.59 & 369.92 & 0.942 & 3.07 & 0.87 & 0.972 \\
\hline
\end{tabular}


2002). Therefore, a small proportion of electrode surface area is accessible for ion electrosorption. In addition, compared with that at $1.2 \mathrm{~V}$, the utilized surface area for $\mathrm{Na}^{+}$and $\mathrm{Cl}^{-}$ions at $0.8 \mathrm{~V}$ is decreased to 46.05 and $39.36 \mathrm{~m}^{2} / \mathrm{g}$, respectively. The explanation is that the effect of EDL overlapping increases with decreasing the applied voltage. Under this condition, carbon aerogel electrode has more restriction for $\mathrm{NaCl}$ ions accessing the charged surface in electrosorption process.

\section{Conclusion}

In this work, the fundamental aspect of electrosorption of $\mathrm{NaCl}$ was investigated. Due to the good double layer capacitive characteristics, nanostructured carbon aerogel has been shown to successfully remove $\mathrm{NaCl}$ from aqueous solutions. The mechanism is mainly due to electrostatic interactions, associated with EDL formation on the charged surface of carbon electrode. Therefore, the regeneration of the electrodes can be achieved by depolarization of each electrode. Based on these experimental data, the electrosorption performance, as well as EDL capacitance and electrosorption capacity, can be raised by increasing the applied voltage and solution concentration, and thereby, more surface area can be utilized to electroadsorb ions from aqueous solutions. Three factors can explain this phenomenon: (1) the high polarization of carbon electrodes corresponds to stronger electrostatic attraction; (2) the high solution concentration enhances the transport rate of ions, as a result of the higher concentration gradient; and (3) the double layer compression under high applied potential and solution concentration can reduce the effect of EDL overlapping, accompanied with more available surface area for electrosorption of ions. The results of this work are very important in promoting CDI processes and their practical use for water purification and desalination.

Acknowledgments The authors acknowledge the supports of the National Science Council of Taiwan under Grant No. NSC- 99-2218E-029-003.

\section{References}

Anderson MA, Cudero AL, Palma J (2010) Capacitive deionization as an electrochemical means of saving energy and delivering clean water. Comparison to present desalination practices: will it compete? Electrochim Acta 55:3845-3856

Farmer JC, Fix DV, Mack GV, Pekala RW, Poco JF (1996a) Capacitive deionization of $\mathrm{NaCl}$ and $\mathrm{NaNO}_{3}$ solutions with carbon aerogel electrodes. J Electrochem Soc 143:159-169

Farmer JC, Fix DV, Mack GV, Pekala RW, PoCo JF (1996b) Capacitive deionization of $\mathrm{NH}_{4} \mathrm{ClO}_{4}$ solutions with carbon aerogel electrodes. J Appl Electrochem 26:1007-1018
Farmer JC, Bahowick SM, Harrar JE, Fix DV, Martinelli RE, Vu AK, Carroll KL (1997) Electrosorption of chromium ions on carbon aerogel electrodes as a means of remediating ground water. Energy Fuels 11:337-347

Frackowiak E, Béguin F (2001) Carbon materials for the electrochemical storage of energy in capacitors. Carbon 39:937-950

Gabelich CJ, Tran TD, Suffet IH (2002) Electrosorption of inorganic salts from aqueous solution using carbon aerogels. Environ Sci Tech 36:3010-3019

Hou CH, Liang CD, Yiacoumi S, Dai S, Tsouris C (2006) Electrosorption capacitance of nanostructured carbon-based materials. J Coll Interf Sci 302:54-61

Hunter RJ (2001). Foundations of Colloid Science, 2nd edn, Oxford University Press, Oxford

Jung HH, Hwang SW, Hyun SH, Lee KO, Kim GT (2007) Capacitive deionization characteristics of nanostructured carbon aerogel electrodes synthesized via ambient drying. Desalination 216:377-385

Kim YJ, Choi JH (2010) Enhanced desalination efficiency in capacitive deionization with an ion-selective membrane. Sep Purif Tech 71:70-75

Koresh JE, Soffer A (1987) The carbon molecular-sieve membranes: general properties and the permeability of $\mathrm{CH}_{4}$ and $\mathrm{H}_{2}$ mixture. Sep Sci Tech 22:973-982

Li H, Zou L (2011) Ion-exchange membrane capacitive deionization: a new strategy for brackish water desalination. Desalination 275:62-66

Li HB, Zou LD, Pan LK, Sun Z (2010) Novel graphene-like electrodes for capacitive deionization. Environ Sci Tech 44:8692-8697

Noked M, Avraham E, Soffer A, Aurbach D (2009) The ratedetermining step of electroadsorption processes into nanoporous carbon electrodes related to water desalination. J Phys Chem C 113:21319-21327

Okoye AI, Ejikeme PM, Onukwuli OD (2010) Lead removal from wastewater using fluted pumpkin seed shell activated carbon: adsorption modelling and kinetics. Int $\mathrm{J}$ Environ Sci Tech 7:793-800

Onundi YB, Mamun AA, Al Khatib MF, Ahmed YM (2010) Adsorption of copper, nickel and lead ions from synthetic semiconductor industrial wastewater by palm shell activated carbon. Int J Environ Sci Tech 7:751-758

Oren Y (2008) Capacitive delonization (CDI) for desalination and water treatment-past, present and future (a review). Desalination 228:10-29

Pröbstle H, Wiener M, Fricke J (2003) Carbon aerogels for electrochemical double layer capacitors. J Porous Mat 10:213-222

Seo SJ, Jeon H, Lee JK, Kim GY, Park D, Nojima H, Lee J, Moon SH (2010) Investigation on removal of hardness ions by capacitive deionization (CDI) for water softening applications. Water Res 44:2267-2275

Villar I, Suarez-De la Calle DJ, González Z, Granda M, Blanco C, Menéndez R, Santamaría R (2011) Carbon materials as electrodes for electrosorption of $\mathrm{NaCl}$ in aqueous solutions. Adsorpt J Int Adsorpt Soc 17:467-471

Xu P, Drewes JE, Heil D, Wang G (2008) Treatment of brackish produced water using carbon aerogel-based capacitive deionization technology. Water Res 42:2605-2617

Yang KL, Yiacoumi S, Tsouris C (2003) Electrosorption capacitance of nanostructured carbon aerogel obtained by cyclic voltammetry. J Electroanal Chem 540:159-167

Ying TY, Yang KL, Yiacoumi S, Tsouris C (2002) Electrosorption of ions from aqueous solutions by nanostructured carbon aerogel. J Coll Interf Sci 250:18-27

Zou LD, Li LX, Song HH, Morris G (2008) Using mesoporous carbon electrodes for brackish water desalination. Water Res 42:2340-2348 